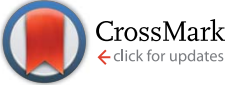

Cite this: RSC Adv., 2016, 6, 46037
Received 28th January 2016

Accepted 3rd May 2016

DOI: $10.1039 / c 6 r a 02585 d$

www.rsc.org/advances

\section{Synthesis of a fluorinated graphene oxide-silica nanohybrid: improving oxygen affinity}

A. Maio, ${ }^{a}$ D. Giallombardo, ${ }^{a}$ R. Scaffaro, ${ }^{\star a}$ A. Palumbo Piccionello ${ }^{b}$ and I. Pibiri ${ }^{\star b}$

An easy method to achieve a fluorinated graphene oxide-silica nanohybrid (GOSF) is presented. Graphene oxide (GO) was synthesized by Hummer's modified method, the GO-silica nanohybrid (GOS) was obtained via Fischer esterification, the fluorinated moiety (3-pentadecafluoroheptyl-5-perfluorophenyl-1,2,4oxadiazole) was introduced by nucleophilic substitution operated by the hydroxyl functionalities onto the GOS surface. Full characterization of the new materials confirmed the formation of covalent bonds between the graphene oxide/silica hybrid matrix and the fluorinated moieties. The proposed methodology offers an easy way to get fluorinated carbon/silica hybrid nanomaterials avoiding the harsh reaction conditions usually involved in the preparation of fluorinated materials, and allowing the selective immobilization of specific fluorotails. Moreover, performed oxygen uptake and release kinetics showed that the introduction of fluorinated moieties increases the oxygen exchange, making the material interesting for prospective applications in the biomedical field, as oxygen delivery system, as filler for biocompatible materials, and in the preparation of membranes for the purification of water.

\section{Introduction}

Graphene oxide (GO) is one of the most extensively studied forms of functionalized graphene as it is readily available by exfoliating oxidized graphite, ${ }^{\mathbf{1}}$ and it is the most common intermediate in the synthesis of reduced graphene. ${ }^{\mathbf{1 - 4}}$

The coexistence of aromatic and non-aromatic domains in a double honeycomb composed by both $\mathrm{sp}^{2}$ and $\mathrm{sp}^{3}$ hybridized carbon atoms, as well as the presence of a variegated assortment of functional moieties, defects, holes and cavities, contribute to the attainment of unique and intriguing properties from a chemical-physical point of view. ${ }^{5}$

The versatility of GO makes it particularly suitable for the synthesis of graphene-based materials, owing to the possibility of further functionalizing GO lamellae with a large variety of compounds. In fact, one can either covalently attach specific moieties onto GO by exploiting its highly reactive oxygen moieties (e.g. carboxyl, epoxy and hydroxyl) or physically immobilize planar drugs via $\pi-\pi$ stacking interactions, thus involving graphenic aromatic domains. ${ }^{1-5}$

Nevertheless, some issues still must be solved. Recent studies on GO structural modelling focused on its metastability, thus suggesting that GO has not to be considered as a static compound with a given set of functional moieties. ${ }^{6,7}$ Despite

${ }^{a}$ Department of Civil, Aerospace, Environmental, Materials Engineering, University of Palermo, Viale delle Scienze - Parco d'Orleans II, Ed. 6, 90128, Palermo, Italy. E-mail: roberto.scaffaro@unipa.it; Tel: +3909123863723

${ }^{b}$ Department of Biological, Chemical and Pharmaceutical Sciences and Technologies, University of Palermo, Viale delle Scienze - Parco d'Orleans II, Ed. 17, 90128, Palermo, Italy. E-mail: ivana.pibiri@unipa.it; Tel: +3909123897545 their differences, all the revisions to former models agree on considering GO as a family of closely related materials, or a composite material itself, which composition, dependent on several conditions used within synthesis and purification steps, evolves over time..$^{8,9}$

However, GO-based materials currently find applications in many areas, ranging from solar cells, resonators, electronic devices, supercapacitors, catalyst supports, electronic components to biotechnology, including drug delivery, and biosensing. ${ }^{10-15}$

In this context, GO-silica nanohybrids are currently used in many fields, ranging from optoelectronics to medicine, ${ }^{7-9}$ because of the potentialities for electrical applications, their chemical inertia and cytocompatibility.

On the other side growing interest of the materials community has been posed on the functionalization of GO with fluorine. For instance, fluorinated GO has been proven to be the first carbon material for magnetic resonance imaging without the addition of magnetic nanoparticles, ${ }^{\mathbf{1 6}}$ moreover, it has proven to absorb NIR-laser energy and efficiently transform it into heat, thus making promises to be used as a contrast agent for MRI, ultrasound and photoacoustic imaging, and also as targetable drug carrier and NIR laser inducible hyperthermic material that can ablate thermosensitive cancer cells. ${ }^{17,18}$

The introduction of fluorine on the basal planes of graphene has been realized by several methodologies, ${ }^{19}$ such as F plasma, or exposure to $\mathrm{F}_{2}$ or $\mathrm{XeF}_{2}$ at high temperature. Fluorinated graphene has also been obtained by exfoliation method from graphite fluoride. However, plasma and high temperature can damage the material and are not recommended. Electrochemical 
processes have been also reported for the synthesis of graphene oxyfluoride, or the use of extremely corrosive reagent hydrogen fluoride.

A possible alternative to the direct introduction of fluorine is the possibility to introduce perfluorinated moieties, in this case, besides the vantage of mild conditions, the added value is the peculiar ability to dissolve large amounts of physiologically important gases, such as oxygen and carbon dioxide. Functional studies have shown that perfluorinated molecules improve $\mathrm{O}_{2}$ solubility of approximately 50 times, in fact they are known as blood substitutes. ${ }^{20}$

Furthermore, the direct fluorination of graphene oxide can lead to a wide distribution of fluorinated moieties, due to the aforementioned presence of a variegated family of oxygen groups in GO, which, as obvious, are prone to react in different ways. Using a GO decorated with silica nanoparticles, instead, can be a successful strategy where the selective attachment of a specific type of fluorinated moieties is preferred.

Aim of this work was to explore a new way for the introduction of perfluoroalkyl chains onto the surface of a GO-silica nanohybrid material (GOS) and study the interesting features of the so-obtained new material, in this specific case by analyzing its oxygen affinity.

Both graphene based materials ${ }^{21}$ and silica based nanohybrids $^{22}$ are frequently reported as biocompatible materials. The idea to combine the intriguing features of these two materials, furthermore introducing perfluorinated moieties in order to maximize the ability of the material to uptake and release oxygen, would greatly increase the interest towards this novel nanohybrid in the biocompatible materials field, since it is known that oxygen is essential for cellular metabolism and organ functioning and the lack of sufficient oxygen at the cellular level causes severe damage to cells and tissues. ${ }^{23}$

In this context, the introduction of perfluorinated 1,2,4oxadiazoles derivatives is interesting, due to their wide application in synthesis ${ }^{24-28}$ and in medicinal chemistry, ${ }^{26-28}$ and also as advanced materials. ${ }^{29}$

Their biocompatibility and inertness, associated to the ability to dissolve a larger amount of oxygen make perfluoroalkylated oxadiazoles very interesting moieties to be introduced in materials for biomedical and eco-compatible applications.

\section{Experimental}

\section{Materials}

Neat graphite (grade Ma 399, $45 \mu \mathrm{m}$ ) was purchased by NGS Naturgraphit (Germany), fumed silica nanoparticles, Aerosil@ OX50, were provided by Evonik Industries (Germany).

Pentadecafluoroheptyl amidoxime has been prepared as reported. ${ }^{30}$ Pentafluorobenzoyl chloride, potassium tert-butoxide, $\mathrm{H}_{3} \mathrm{PO}_{4}, \mathrm{H}_{2} \mathrm{SO}_{4}, \mathrm{KMnO}_{4}, \mathrm{HCl}, \mathrm{H}_{2} \mathrm{O}_{2}$, toluene, pyridine, dimethylformamide (DMF), tetrahydrofuran (THF), $\mathrm{C}_{2} \mathrm{H}_{5} \mathrm{OH}$ and $\mathrm{HCOOH}$ were purchased by Sigma Aldrich.

Flash silica gel (200-400 mesh), light petroleum (fraction boiling in the range of $40-60{ }^{\circ} \mathrm{C}$ ) and ethyl acetate were purchased by Merck.
Dialysis was performed by Spectra/Por ${ }^{\circledR}$ Standard RC tubing; MWCO 12-14 kDa.

All the reactants were used as received without any further purification.

\section{Synthetic procedures}

Synthesis of GO. GO was synthesized by oxidation of neat graphite, according to a Hummers modified method. ${ }^{2}$ Briefly, the graphite powder and $\mathrm{KMnO}_{4}$ were premixed in the solid state and then added to a mixture of $\mathrm{H}_{2} \mathrm{SO}_{4}$ and $\mathrm{H}_{3} \mathrm{PO}_{4}$, the reaction was stopped with $\mathrm{H}_{2} \mathrm{O}_{2} 30 \mathrm{wt} \%$ in $\mathrm{H}_{2} \mathrm{O}$, and ice. For the work up, several centrifugations were carried out with $\mathrm{HCl}$, water and $\mathrm{C}_{2} \mathrm{H}_{5} \mathrm{OH}$. Other details can be found elsewhere. ${ }^{2,31,32}$

Synthesis of GOS. For the synthesis of GOS nanohybrids, GO $(0.12 \mathrm{~g})$ and silica nanoparticles $(0.12 \mathrm{~g})$ were dispersed in water $(100 \mathrm{~mL})$ with $2 \% \mathrm{HCOOH}$, sonicated at $50{ }^{\circ} \mathrm{C}$ for 1 hour and then transferred to a Teflon-coated crystallizer, where the dispersion was magnetic stirred at $80{ }^{\circ} \mathrm{C}$ for 3 hours, thereafter the temperature was increased up to $120^{\circ} \mathrm{C}$. Of course, as long as the solvent was present, the temperature remained constant at $100{ }^{\circ} \mathrm{C}$, after about 25 minutes the total evaporation of water occurred and the gel-like slurry was maintained at $120^{\circ} \mathrm{C}$ for 35 minutes. Finally, a brown film was peeled off, dispersed in THF under ultra-sonication treatment, thoroughly washed and dialyzed for $24 \mathrm{~h}$ in order to remove the silica not covalently bonded. Characterization details are reported elsewhere. ${ }^{15}$

Synthesis of 3-pentadecafluoroheptyl-5-pentafluorophenyl1,2,4-oxadiazole (1). The synthesis has been achieved as previously reported ${ }^{33-36}$ by mixing pentadecafluoroheptyl amidoxime (1.28 g, $3 \mathrm{mmol})$, pyridine $(0.26 \mathrm{~g}, 3.3 \mathrm{mmol})$ and pentafluorobenzoyl chloride ( $0.76 \mathrm{~g}, 3.3 \mathrm{mmol})$, stirring in toluene (30 $\mathrm{mL}$ ) at $0{ }^{\circ} \mathrm{C}$ for $10 \mathrm{~h}$. Evaporation of the solvent gave a residue that was treated with water and refluxed for $2 \mathrm{~h}$. Chromatography of the residue gave 3-pentadecafluoroheptyl-5pentafluorophenyl-1,2,4-oxadiazole (1) (1.47 g, 81\%): mp, 37$38{ }^{\circ} \mathrm{C}$ (from petroleum). ${ }^{19} \mathrm{~F} \mathrm{NMR}\left(\mathrm{CDCl}_{3}\right) \delta: 79.68(\mathrm{t}, 3 \mathrm{~F}, J=13.0$ $\mathrm{Hz}), 113.54(\mathrm{t}, 2 \mathrm{~F}, J=12.7 \mathrm{~Hz}), 121.63(\mathrm{~s}, 2 \mathrm{~F}), 122.29(\mathrm{~s}, 4 \mathrm{~F})$, 122.97 to $123.0(\mathrm{~m}, 2 \mathrm{~F}), 126.37$ to $126.42(\mathrm{~m}, 2 \mathrm{~F}), 133.28$ to $133.45(\mathrm{~m}, 2 \mathrm{~F}), 142.97(\mathrm{tt}, 1 \mathrm{~F}, J=6.5$ and $21.1 \mathrm{~Hz}), 158.32$ to $158.54(\mathrm{~m}, 2 \mathrm{~F})$. GC-MS m/z: $604\left(\mathrm{M}^{+}, 100 \%\right)$. Anal. calcd for $\mathrm{C}_{15} \mathrm{~F}_{20} \mathrm{~N}_{2} \mathrm{O}$ : C, 29.82; N, 4.64; found C, 29.75; N, 4.58.

Synthesis of GOSF. A suspension of GOS $(0.080 \mathrm{~g})$ in absolute DMF (6 mL) was sonicated for 10 minutes. Potassium tert-butoxide $(0.312 \mathrm{~g})$ was added, and the reaction mixture was stirred at room temperature for fifteen minutes. Compound 1 (1.440 g) was added in one portion, and the resulting suspension was stirred at room temperature overnight ( 24 hours). Ethyl acetate $(30 \mathrm{~mL})$ was added to dilute the excess of fluorinated reagent, and the solution was centrifuged for ten minutes at $4000 \mathrm{rpm}$. The solid $(65.6 \mathrm{mg}$ ) was recovered by filtration and purified by repeated rinsing and filtration with further organic solvent.

\section{Characterization}

Melting point for $\mathbf{1}$ was determined on a REICHARTTHERMOVAR hot-stage apparatus. ${ }^{1} \mathrm{H}$ NMR spectra in solution were recorded on a BRUKER AC 250 E spectrometer and 
were taken with TMS as an internal standard. ${ }^{19} \mathrm{~F}$ NMR spectra in solution were recorded on a BRUKER Avance $300(282.3 \mathrm{MHz})$ spectrometer and were taken with $\mathrm{CFCl}_{3}$ as internal standard (b before the multiplicity stands for broad signal). GC/MS determinations were carried out on a GC-MS Shimadzu QP-2010.

Flash chromatography was performed by using silica gel (Merck, 0.040-0.063 mesh) and mixtures of light petroleum (fraction boiling in the range of $40-60{ }^{\circ} \mathrm{C}$ ) and ethyl acetate in various ratios.

FTIR analysis for solid samples was carried out by using a Perkin-Elmer FT-IR/NIR Spectrum 400 spectrophotometer. The spectra were recorded in the range $4000-400 \mathrm{~cm}^{-1}$.

Micro-Raman spectroscopy was performed by means of a Renishaw InVia instrument, with diode laser excitation at 633 $\mathrm{nm}$ and spectral resolution $1 \mathrm{~cm}^{-1}$. Measurements in at least five different sample positions have been repeated for each treatment. Analysis of the spectra has been done after subtraction of a linear baseline for the samples GOS and GOSF ${ }^{37-39}$ and subsequent normalization of each curve to the $G$ band. ${ }^{39}$

${ }^{13} \mathrm{C}$ Cross Polarization Magic Angle Spinning Nuclear Magnetic Resonance $\left({ }^{13} \mathrm{C}\left\{{ }^{1} \mathrm{H}\right\}\right.$ CP-MAS NMR) spectra have been acquired at room temperature by a Bruker Avance II $400 \mathrm{MHz}$ (9.4 T) spectrometer, operating at $100.63 \mathrm{MHz}$ for ${ }^{13} \mathrm{C} . \dagger$ All experiments have been performed with a MAS spinning rate of 8 $\mathrm{kHz}, 1024$ scans a contact time of $0.6 \mathrm{~ms}$, a delay time of $10 \mathrm{~s}$ and an excitation pulse on the ${ }^{1} \mathrm{H}$ nuclide of $4.5 \mu \mathrm{s}$. A standard sample of adamantane has been used as an external reference and all samples were placed in a $4 \mathrm{~mm}$ zirconia rotors sealed with KEL-F caps.

${ }^{13} \mathrm{C}$ Direct Polarization (DP) solid state spectra with a MAS spinning rate of $8 \mathrm{kHz}, 1024$ scans, a delay time of $10 \mathrm{~s}$ and an excitation pulse on the ${ }^{13} \mathrm{C}$ nuclide of $4.5 \mu \mathrm{s}$. A standard sample of adamantane has been used as an external reference and all samples were placed in a $4 \mathrm{~mm}$ zirconia rotors sealed with KELF caps.

${ }^{19}$ F Direct Polarization (DP) solid state spectra were acquired under fast MAS conditions by a spinning rate of $25 \mathrm{kHz}$. Spectra were acquired with an excitation pulse on the ${ }^{19} \mathrm{~F}$ nuclide of $4.0 \mu \mathrm{s}$, a delay time of $3 \mathrm{~s}$ and 8 scans.

The morphology of nanohybrids was observed by scanning electron microscopy, carried out in an ESEM FEI QUANTA 200 microscope on both nanoparticles and nanostructured films. In this latter case, the samples were cryo-fractured in liquid nitrogen to investigate the morphology of both longitudinal and cross section. The samples were attached on an aluminum stub using an adhesive carbon tape and then sputter coated with gold (Sputtering Scancoat Six, Edwards) for $90 \mathrm{~s}$ under argon atmosphere before imaging to avoid electrostatic discharge during the tests.

The surface composition was studied with a Phenom ProX, PhenomWorld equipped with EDX probe to detect the presence of C, O, Si, N and F.

\footnotetext{
$\dagger$ NMR experimental data were provided by Centro GrandiApparecchiature-UniNetLab-University of Palermo funded by P.O.R. Sicilia 2000-2006, Misura 3.15 Quota Regionale.
}

XPS investigations were carried out by using a PHI 5000 Versaprobe-II system. The spectrometer was calibrated by assuming the binding energy $(\mathrm{BE})$ of the $\mathrm{Au} 4 \mathrm{f}_{7 / 2}$ line to be $84.0 \mathrm{eV}$ with respect to the Fermi level. Both extended spectra (survey $187.85 \mathrm{eV}$ pass energy, $0.5 \mathrm{eV}$ per step, $0.05 \mathrm{~s}$ per step) and detailed spectra (for $\mathrm{C} 1 \mathrm{~s}$ and $\mathrm{O} 1 \mathrm{~s}-11.75 \mathrm{eV}$ pass energy, $0.05 \mathrm{eV}$ per step, $0.2 \mathrm{~s}$ per step) were collected with a standard $\mathrm{Al} \mathrm{K} \alpha$ source working at $300 \mathrm{~W}$. The standard deviation in the BE values of the XPS line is $0.10 \mathrm{eV}$. The atomic percentage, after a Shirleytype background subtraction, was evaluated by using the PHI sensitivity factors. The peak positions were corrected for eventual charging effects by considering the $\mathrm{C}$ 1s peak at $284.8 \mathrm{eV}$ and evaluating the BE differences. ${ }^{39}$ The curve fitting was carried out by means of an iterative least square procedure making use of Voight functions on Shirley-type background..$^{15,32,39}$

Oxygen solubility measurements were performed, as previously reported, ${ }^{35,36}$ by using a digital oximeter, with a Schott Gerade $120 \mathrm{~mm}$ probe having a membrane with an exterior Teflon layer.

Measures were recorded by placing the electrode tip into the bulk phase at $80 \mathrm{~mm}$ distance from the air-liquid interface. Data from oxygen saturated aqueous suspensions $(20 \mathrm{~mL})$ containing GOS and GOSF at $0.5 \mathrm{mg} \mathrm{mL}^{-1}$, were taken at atmospheric pressure. In particular, each suspension was initially stirred with a magnetic stir bar while pure oxygen was continuously bubbled. The temperature of each suspension was adjusted to $25{ }^{\circ} \mathrm{C}$ by using a thermostated oil bath. Once the suspension reached a stable maximum oxygen concentration (saturated solution), bubbling was stopped and the release of dissolved oxygen was determined by evaluating the change in the oxygen solubility (desaturation) as a function of time.

Experiments have been conducted in triplicate and the statistic analysis according to T-student test allowed to calculate $P<6 \times 10^{-4}$.

\section{Results and discussion}

GO was synthesized by oxidizing neat graphite by a quite common method ${ }^{2}$ and decorated with silica nanoparticles via a rapid and eco-friendly hydrothermal treatment. ${ }^{15}$

As a result, the most reactive sites of GO, such as epoxy rings and carboxyls, were involved in reactions with silanol groups of silica, thus allowing the achievement of graphene oxide nanoplatforms equipped with hydroxyls and silica nanoparticles. These latter ones, bearing silanols were selectively exploited to anchor perfluorinated 1,2,4-oxadiazoles via a facile aromatic nucleophilic substitution (SNA). The remaining -OH moieties of GO, located in those zones not covered by silica, were capable to operate the covalent binding of 1 via the same SNA mechanism. The pathway followed is schematized in Fig. 1.

Several characterization techniques were used to demonstrate the effective grafting of fluorotails onto GOS matrix and to investigate the structure-properties relationships of the nanohybrid herein synthesized: more in detail, the characterization of the materials has been performed by FTIR, Raman spectroscopy, SEM-EDX, Magic Angle Spinning Nuclear Magnetic Resonance $\left({ }^{13} \mathrm{C}\left\{{ }^{1} \mathrm{H}\right\}\right.$ MAS NMR and ${ }^{19} \mathrm{~F}$ MAS NMR) and XPS analysis. 

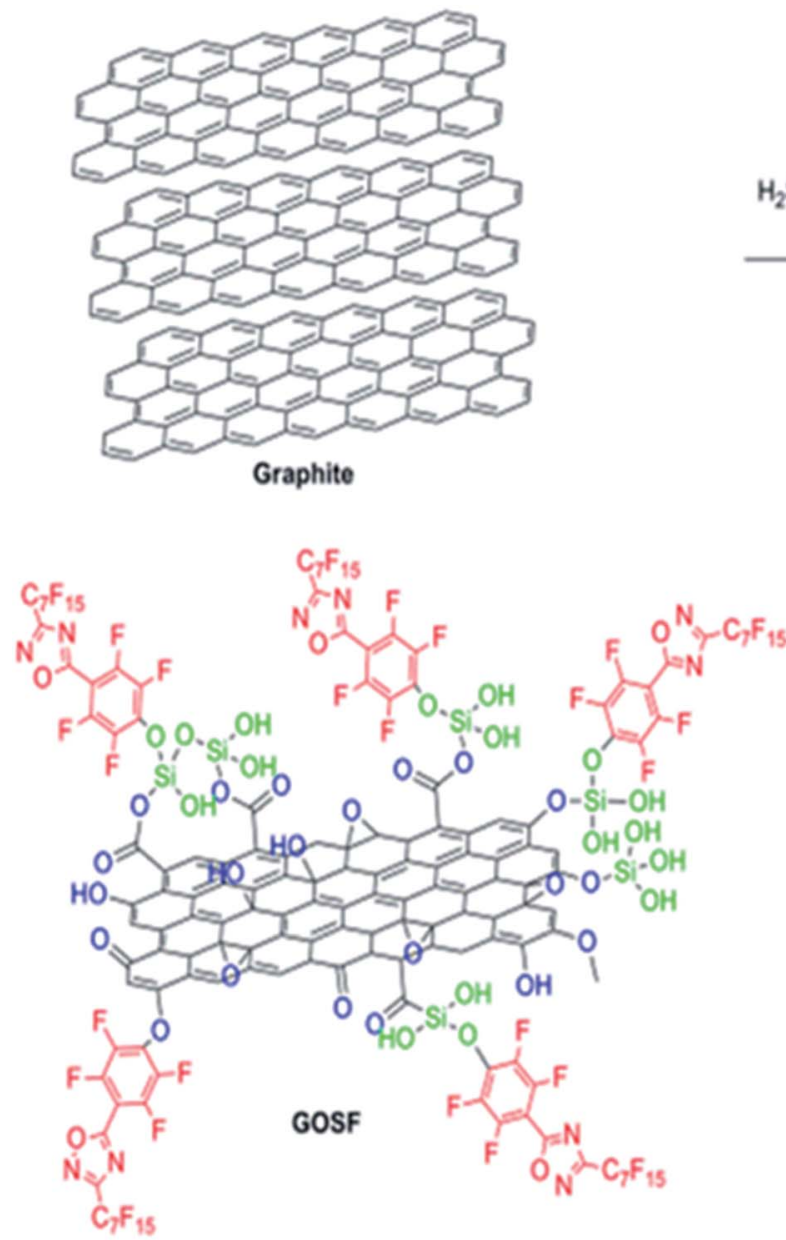
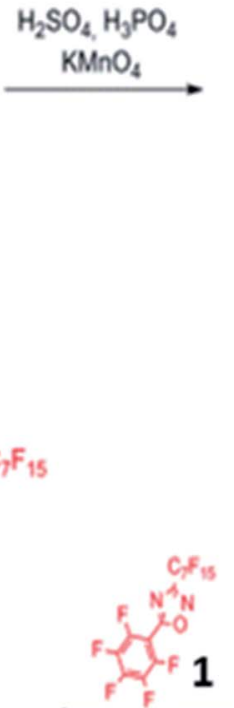

tBuOK' DMF $r T$

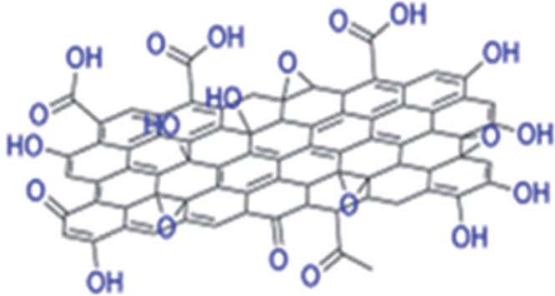

Graphene Oxide (GO)
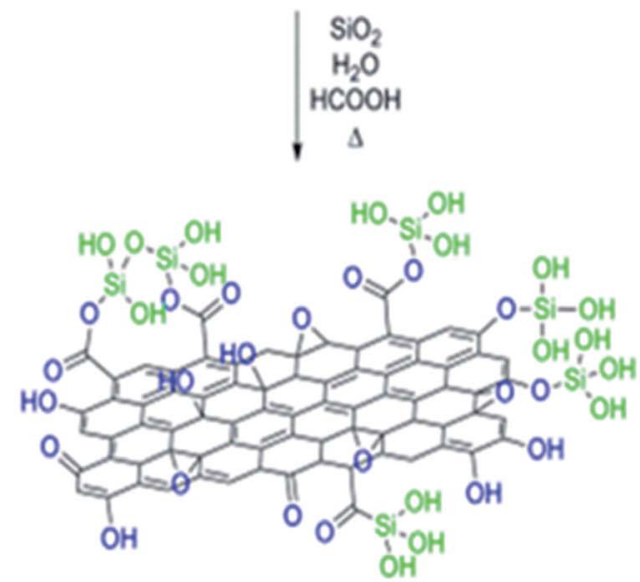

GOS

Fig. 1 Route to GOSF: GO was synthesized via the modified Hummers method, ${ }^{13}$ and silica-GO (GOS) composite was prepared by Fischer esterification in water and $2 \%$ of $\mathrm{HCOOH}$ at $120{ }^{\circ} \mathrm{C}$ between the $-\mathrm{COOH}$ and epoxy groups of $\mathrm{GO}$ and the $-\mathrm{OH}$ moieties of the silica. The functionalization with fluorinated tails has been realized by aromatic nucleophilic substitution. In particular, a 3-pentadecafluoroheptyl-5perfluorophenyl-1,2,4-oxadiazole (1), has been introduced very easily by nucleophilic substitution operated by the oxygenated functionalities present on the surface of the GO-silica nanohybrid.

FTIR spectra of GOS and GOSF are provided in Fig. 2, together with those of GO and $\mathbf{1}$ for sake of comparison.

Compound 1 shows absorption peaks related to $\mathrm{C}-\mathrm{F}$ bond arising from perfluoroalkyl chain and perfluorophenyl ring at $1200 \mathrm{~cm}^{-1}, 1140 \mathrm{~cm}^{-1}$ and $970 \mathrm{~cm}^{-1}$ whereas the double peak located at $1570 \mathrm{~cm}^{-1}$ and $1650 \mathrm{~cm}^{-1}$ could be ascribed to $\mathrm{C}=\mathrm{N}$ bond of oxadiazole and $\mathrm{C}=\mathrm{C}$ of phenyl ring.

FTIR spectrum of GO is consistent with literature data. ${ }^{1-6,15,31,40}$

Although the end-groups refer substantially to $-\mathrm{OH}, \mathrm{C}-\mathrm{O}-\mathrm{C}$ and $-\mathrm{COOH}$, the presence of a highly aromatic and variegated environment surrounding oxygen moieties determines the coexistence of phenols, epoxy, ethers, lactols, lactones, aldehydes, ketones, aromatic acids, and many other moieties, besides water molecules adsorbed.$^{40}$ Due to these features, GO was found to absorb practically within the entire spectral range, especially at lower wavenumbers. ${ }^{40}$

Nevertheless, the broad absorption band in the range 3750$3200 \mathrm{~cm}^{-1}$ is traditionally assigned to $-\mathrm{OH}$ stretching due to phenols, carboxyls and water., ${ }^{1,2}$ Two well recognizable bands are centred at around $1720 \mathrm{~cm}^{-1}$ and $1624 \mathrm{~cm}^{-1}$, with the former being undoubtedly assigned to carbonyls while the latter presumably originating by bending modes of water molecules integrated into $\mathrm{GO}$ structure or by $\mathrm{C}=\mathrm{C}$ of graphenic sublattice.

At wavenumbers below $1250 \mathrm{~cm}^{-1}$ a bunch of overlapping signals was proposed to be due to $\mathrm{C}-\mathrm{O}-\mathrm{C}$ and $\mathrm{C}-\mathrm{OH}$ features, under the form of either epoxy, cyclic ethers and organic alcohols. As one can see, the bands assigned to $-\mathrm{OH}$ moieties (located at $1000 \mathrm{~cm}^{-1}$ and $3000-3600 \mathrm{~cm}^{-1}$ ) decrease after the grafting of nanosilica, as well as those attributable to carboxyl and epoxy groups, whereas in the range $1200-900 \mathrm{~cm}^{-1}$ it is possible to detect a variegated absorption band with two main peaks. The one located at $1080 \mathrm{~cm}^{-1}$ can be attributable to the overlapping of $\mathrm{Si}-\mathrm{O}-\mathrm{Si}, \mathrm{C}-\mathrm{O}-\mathrm{C}$ and $\mathrm{Si}-\mathrm{O}-\mathrm{C}$ bonds ${ }^{15}$ (see bluefilled zone in the spectrum), while the peak centred at 1014 $\mathrm{cm}^{-1}$ can be reasonably assigned to silanols. ${ }^{15}$

Even in this case (see violet-filled zone), a shoulder can be due to residual $-\mathrm{OH}$ moieties of graphene oxide. The prominent peak at around $800 \mathrm{~cm}^{-1}$ could be ascribed to the formation of 


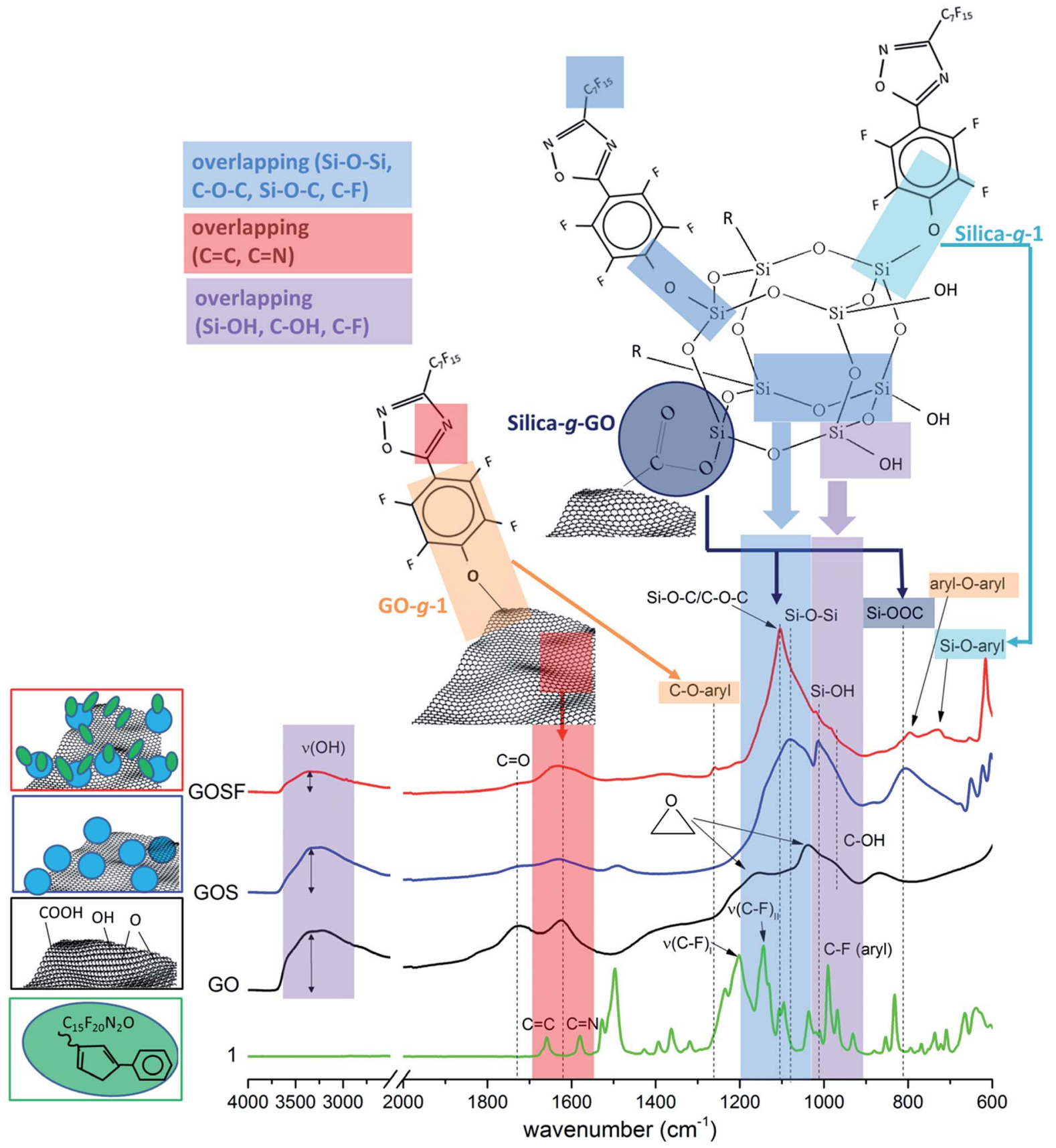

Fig. 2 FTIR spectra of 1 (green), GOS (blue), GOSF (red).

graphenic silicates $(-\mathrm{COO}-\mathrm{Si})$ owing to the reaction between carboxyls of GO and silanols of silica. After SNA covalent binding with 1, instead, $-\mathrm{OH}$ signals were found to dramatically decrease, as well as those referring to silanols. The most prominent band is centred at around $1100 \mathrm{~cm}^{-1}$ and could be ascribed to the formation of $\mathrm{Si}-\mathrm{O}-\mathrm{C}$ bonds due to the grafting of 1 to silica, however the variegated feature and the asymmetric shape of the band suggest that signals arising from $\mathrm{Si}-\mathrm{O}-\mathrm{Si}$ of the silica, $\mathrm{Si}-\mathrm{O}-\mathrm{C}$ of $\mathrm{GO}-\mathrm{g}-\mathrm{SiO}_{2}$ and $\mathrm{GO}-\mathrm{g}-\mathbf{1}$, overlapped. Moreover, even some characteristic absorption peaks of $\mathrm{C}-\mathrm{F}$ fall within the same range, thus making hard and somehow arbitrary to distinguish each contribution. Within the range 1700-
$1550 \mathrm{~cm}^{-1}$ one can observe that even the signals coming from GO $\left(1640 \mathrm{~cm}^{-1}\right)$ and those arising from oxadiazole moiety of 1 combine, thus leading to the insurgence of another variegated band. Three emergent bands, located at $1250 \mathrm{~cm}^{-1}, 790 \mathrm{~cm}^{-1}$ and $690 \mathrm{~cm}^{-1}$, are presumed to respectively indicate the formation of -C-O-aryl, aryl-O-aryl bonds, due to the covalent attachment of $\mathbf{1}$ to graphenic rings, and $\mathrm{Si}-\mathrm{O}$-aryl bonds arising from the covalent attachment of $\mathbf{1}$ to silica. Based on FTIR results, we can only assess that -OH moieties decrease after SNA and that most of the oxygen groups of GO either disappear (due to its partial reduction) or are involved in chemical bonds with silica and 1. Indeed, hydrothermal treatment carried out to 
prepare GOS, as well as the subsequent synthetic step in alkaline environment, are known to partially restore the graphenic structure of the GO, moreover in the presence of oxadiazole, lactones and epoxy groups of GO could react thus further altering the graphenic structure. A closer inspection of the graphenic skeleton of the ternary nanohybrid can be performed by Raman spectroscopy, particularly suitable when the complexity of the system makes extremely difficult to identify carbon-based nanomaterials, owing to its high sensitivity to graphene crystals domains and defects.

Fig. 3a reports the micro-Raman spectra of GO, GOS and GOSF.
All the samples exhibited the main characteristic peaks of graphenic materials: the $\mathrm{D}$ band (close to the $K$ point in the Brillouin zone, arising from the doubly resonant disorderinduced mode $)^{\mathbf{4 0 , 4 1}}$ is centred at around $1345-1350 \mathrm{~cm}^{-1}$, the G-mode (at point $\Gamma$, originating from in-plane vibration of $\mathrm{sp}^{2}$ carbon atoms $)^{40,41}$ is located at $1582-1583 \mathrm{~cm}^{-1}$, the modes resulting from their combination and overtone $(2 \mathrm{D}, \mathrm{D}+\mathrm{G})$ are centred at around $2700-2900 \mathrm{~cm}^{-1} .^{40}$ Furthermore, two less intense Raman modes, namely A and B, are detected at 1100 $\mathrm{cm}^{-1}$ and $1700-1780 \mathrm{~cm}^{-1}$, and respectively assigned to oxygenbonded carbons (either alcohols or ethers) and highly oxygenated non-regular rings, either to 5-8-5 rings resulting from a $\mathrm{C}$
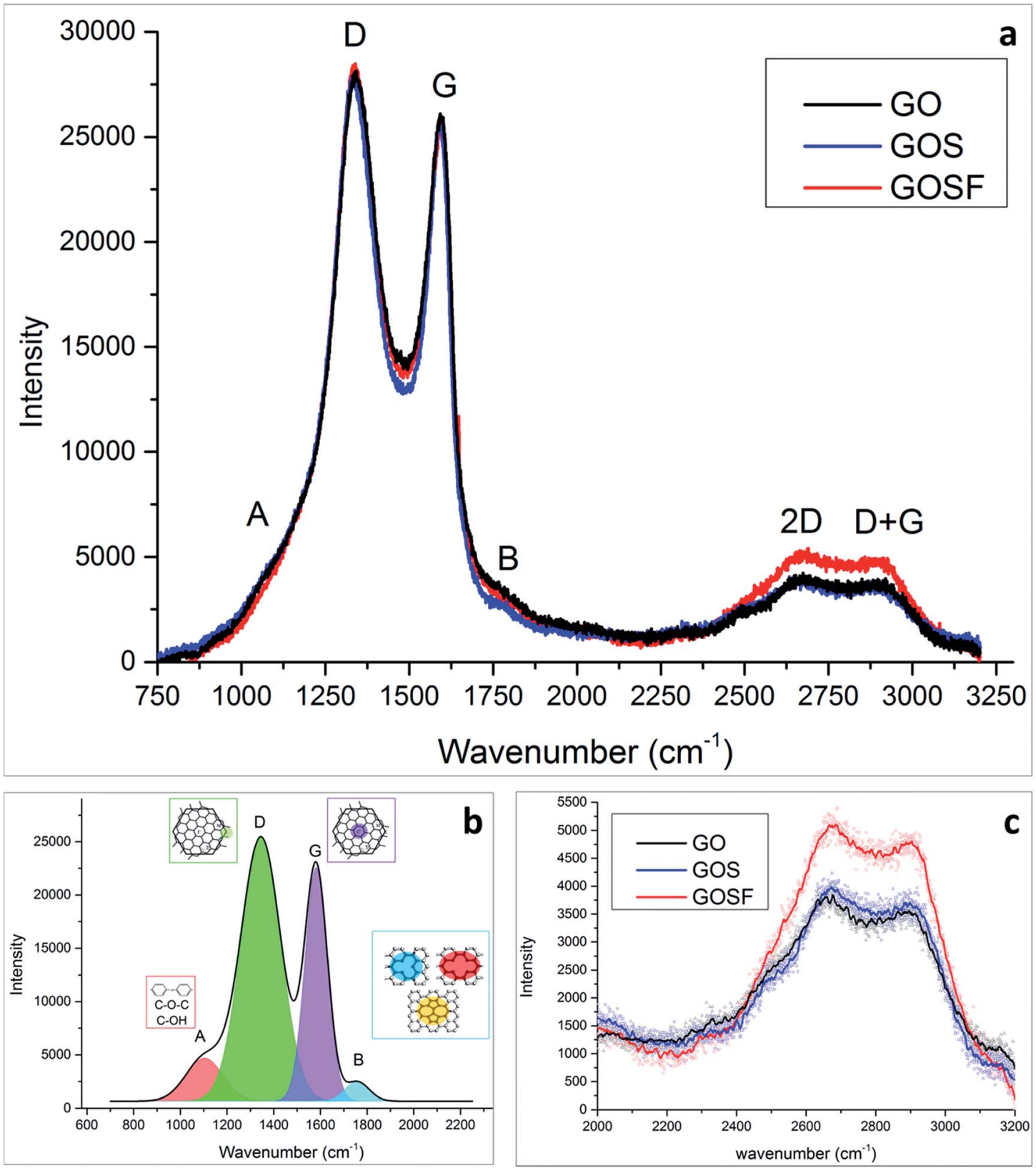

Fig. 3 (a) micro-Raman spectra of GO, GOSF and GOSF; (b) representative multi-peak fitting of a GO spectrum within the wavenumber range $1000-2000 \mathrm{~cm}^{-1}$ (first-order scattering) for the determination of $\mathrm{A}, \mathrm{D}, \mathrm{G}$ and $\mathrm{B}$ modes and the successive calculation of $A_{\mathrm{D}} / A_{\mathrm{G}}$ and $I_{\mathrm{D}} / \mathrm{I}_{\mathrm{G}}$. (c) Magnification of micro-Raman plots collected within the range $2000-3200 \mathrm{~cm}^{-1}$ (second-order scattering). 
di-vacancy or to 5-7-7-5 Stone Wales defects. ${ }^{32}$ The pictorial representation of these contributions is provided in Fig. 3b, together with an exemplificative multi-peak fitting of a GO sample. A closer inspection of the results put into evidence that the samples display no relevant differences within the spectral region related to first-order Raman scattering (i.e. the range $1000-2000 \mathrm{~cm}^{-1}$ ).

The $\mathrm{D} / \mathrm{G}$ intensity ratio $\left(I_{\mathrm{D}} / I_{\mathrm{G}}\right)$, which gives information about the size of $\mathrm{sp}^{2}$ graphenic domains, ${ }^{15,31,32,40-42}$ was found to be practically constant (for GOS) or slightly increased (from 1.12 to 1.15 for GOSF) after functionalization step, whereas the ratio between the integrated areas of $\mathrm{D}$ and $\mathrm{G}\left(A_{\mathrm{D}} / A_{\mathrm{G}}\right)$ was equal to 2 for GO, 1.91 for GOS and 1.94 for GOSF. These features can be explained by considering that the size of graphenic crystals remains practically unaltered, since the immobilization of silica and fluorotails onto GO planes involves only oxygen moieties, as suggested by the depletion of B mode detected for GOSF and especially GOS, with respect to that of pristine GO.

The most relevant changes are detectable in 2D band (see Fig. 3c), which was found increased after fluorination. Since $2 \mathrm{D} / \mathrm{G}$ ratio gives information about the exfoliation degree of
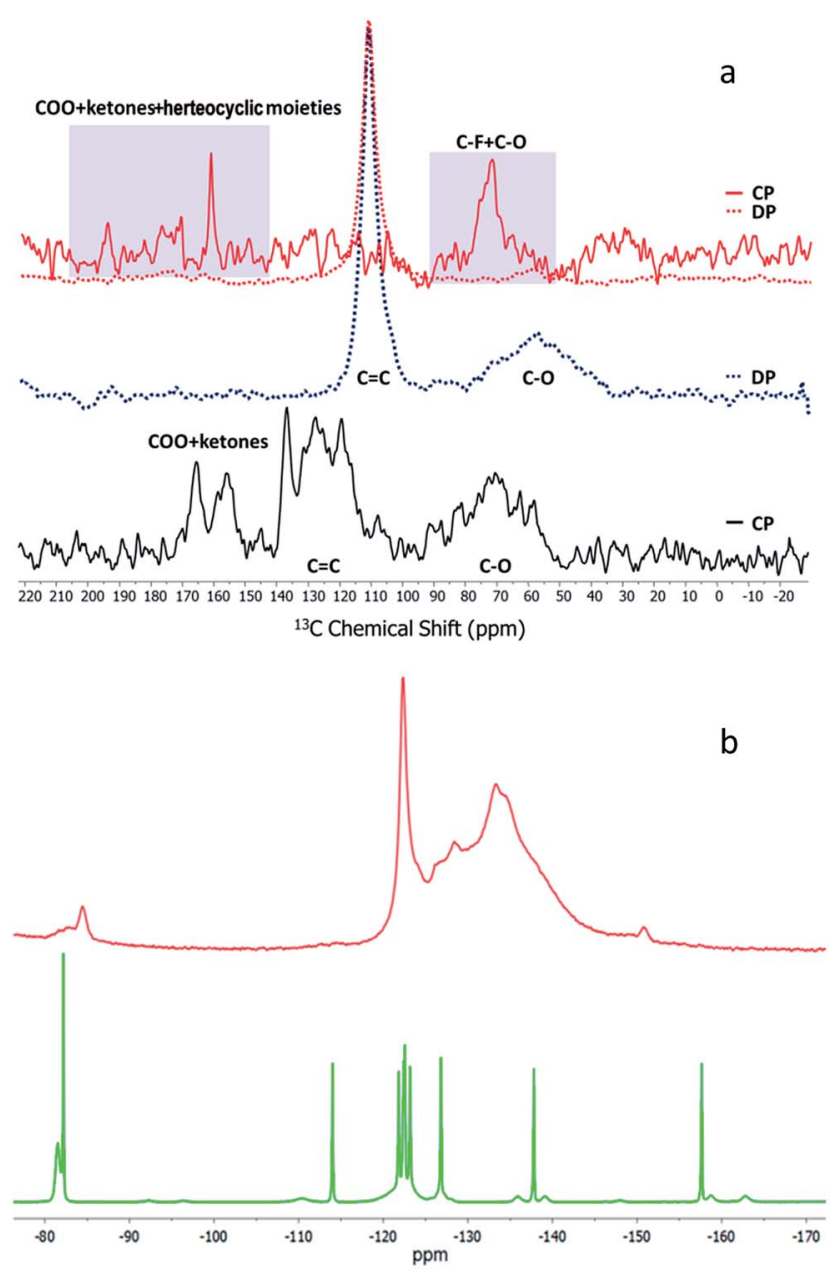

Fig. 4 (a) ${ }^{13} \mathrm{C}\left\{{ }^{1} \mathrm{H}\right\}$ MAS NMR spectra of GO (black), GOS (blue) and GOSF (red) registered in direct (DP) and/or cross polarization (CP) (dotted line); (b) ${ }^{19} \mathrm{~F}$ MAS NMR spectra of GOSF (red) and 1 (green). graphene oxide, ${ }^{15,37}$ one can hypothesize that compound $\mathbf{1}$ is able to intercalate between stacked lamellae, thus increasing the interlayer distance as a result of the formation of aryl ethers.

Solid state ${ }^{13} \mathrm{C}$ NMR spectra of GO, GOS and GOSF are plotted in Fig. $4 \mathrm{a}$

The GOSF spectrum collected in cross polarization $\mathrm{C}-\mathrm{H}$ evidenced the presence of carboxylic functionalities at about 160 ppm and $\mathrm{C}-\mathrm{O}$ at about $70 \mathrm{ppm}$, comparable to the GO signals reported in the same figure. $\mathrm{sp}^{2}$ carbons related to the graphenic matrix are not present in the cross polarization spectrum because of the high distance between $\mathrm{sp}^{2}$ carbons and the protons. Direct polarization experiment evidenced the presence of $\mathrm{sp}^{2}$ carbons as shown in the spectra reported in Fig. 4a. The presence of silica nanoparticles covalently linked to the GO lamellae, did not allow to register for GOS a C-MAS spectrum via cross polarization, the spectrum reported was obtained in direct polarization on ${ }^{13} \mathrm{C}$. It shows the presence of a very intense signal located at $110 \mathrm{ppm}$, related to the $\mathrm{C} \mathrm{\textrm {sp } ^ { 2 }}$ resonance, and a broad signal located at 59 and $71 \mathrm{ppm}$, attributed to $\mathrm{C}-\mathrm{C}-\mathrm{OH}$ and epoxy. This feature is drastically reduced after functionalization (compare GOS to GOSF spectra), thus suggesting that $\mathbf{1}$ is covalently bonded to GOS by nucleophilic substitution, in fully agreement with the results of FTIR analysis.

The effective presence of the fluorinated moieties onto the sidewalls of GO-silica was evaluated by using NMR equipped with a fluorine-probe. Solid state ${ }^{19} \mathrm{~F}$ NMR spectra of GOSF and 1, in Fig. 4b, show the presence of fluorinated moieties in GOSF nanohybrid, in the same chemical shift range observed in the ${ }^{19} \mathrm{~F}$ NMR spectrum of compound 1 .

Notably, the band centered at -157 ppm, assigned to $\mathrm{F}-\mathrm{C}$ (aryl), decreases after the functionalization, thus confirming the effective covalent attachment of 1 onto the GOS via a SNA mechanism.

The morphology of nanohybrids was analyzed by SEM.

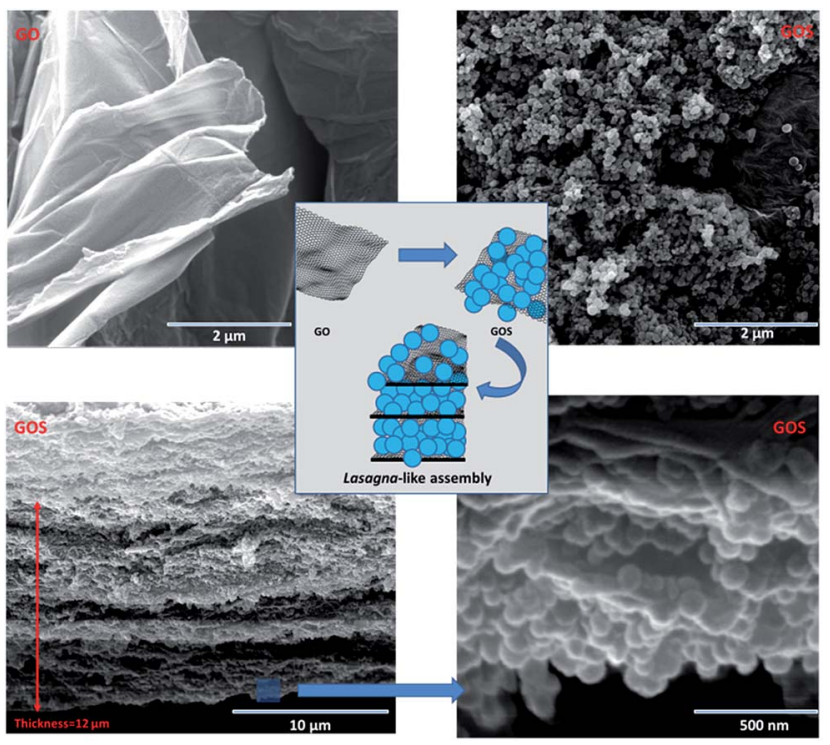

Fig. 5 SEM micrographs of a GO lamella before (top left) and after (top right) silica-decoration, morphology of lasagna-like self-assembled films at different magnification (bottom). 
Fig. 5 reports the micrographs of a GO lamella before (top left) and after (top right) silica-decoration, whereas the structure of the lasagna-like self-assembled films is provided at

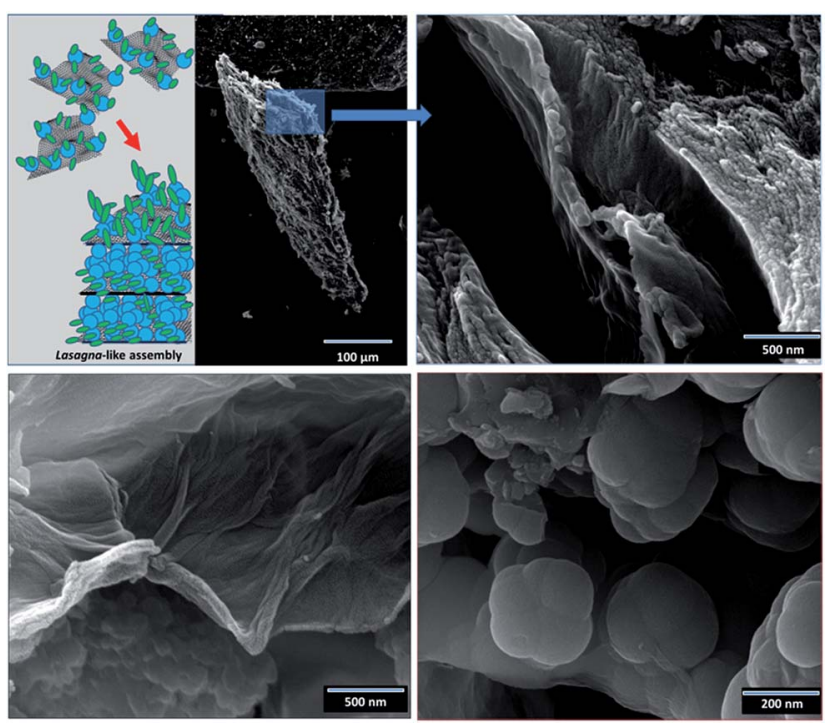

Fig. 6 SEM analysis of GOSF SEM analysis of a GOSF device with detailed micrographs of its hierarchical structure at different magnifications, and a detailed picture of a fluorinated zone not covered by silica (bottom left) different magnifications in the underlying micrographs. Fig. 6 shows the morphology of a GOSF micro-device, constituted by GO lamellae with a discrete distribution of silica nanoparticles. The detailed micrograph of a zone scarcely decorated by silica (bottom left) clearly shows that the graphenic skeleton of GOSF retains the same morphology as pristine GO, thus confirming Raman results previously discussed. The morphology of nanoparticles attached onto graphenic platforms is provided in the bottom right corner of Fig. 6 .

The surface analysis of the nanohybrid, carried out by EDX and XPS, is provided in Fig. 7a-c.

EDX mapping was conducted in two different zones of GOSF, characterized by different degree of silica decoration, with the aim to confirm that fluorotails have been successfully attached onto both graphene oxide and silica. Fig. 7a shows the elemental mapping of $\mathrm{C}, \mathrm{Si}, \mathrm{N}, \mathrm{O}$, F elements (together with the combined map) performed in a zone densely functionalized by silica. The results remark the homogeneous distribution of fluorine and nitrogen, peculiar elements of compound 1. Fig. 7b reports the mapping of the same elements in a zone scarcely decorated by silica. As one can see, fluorine and nitrogen are well recognizable even in the graphenic zones not covered by silica, thus proving that $\mathbf{1}$ is bonded even to graphene oxide basal planes, although these latter regions display the same morphology as pristine GO.
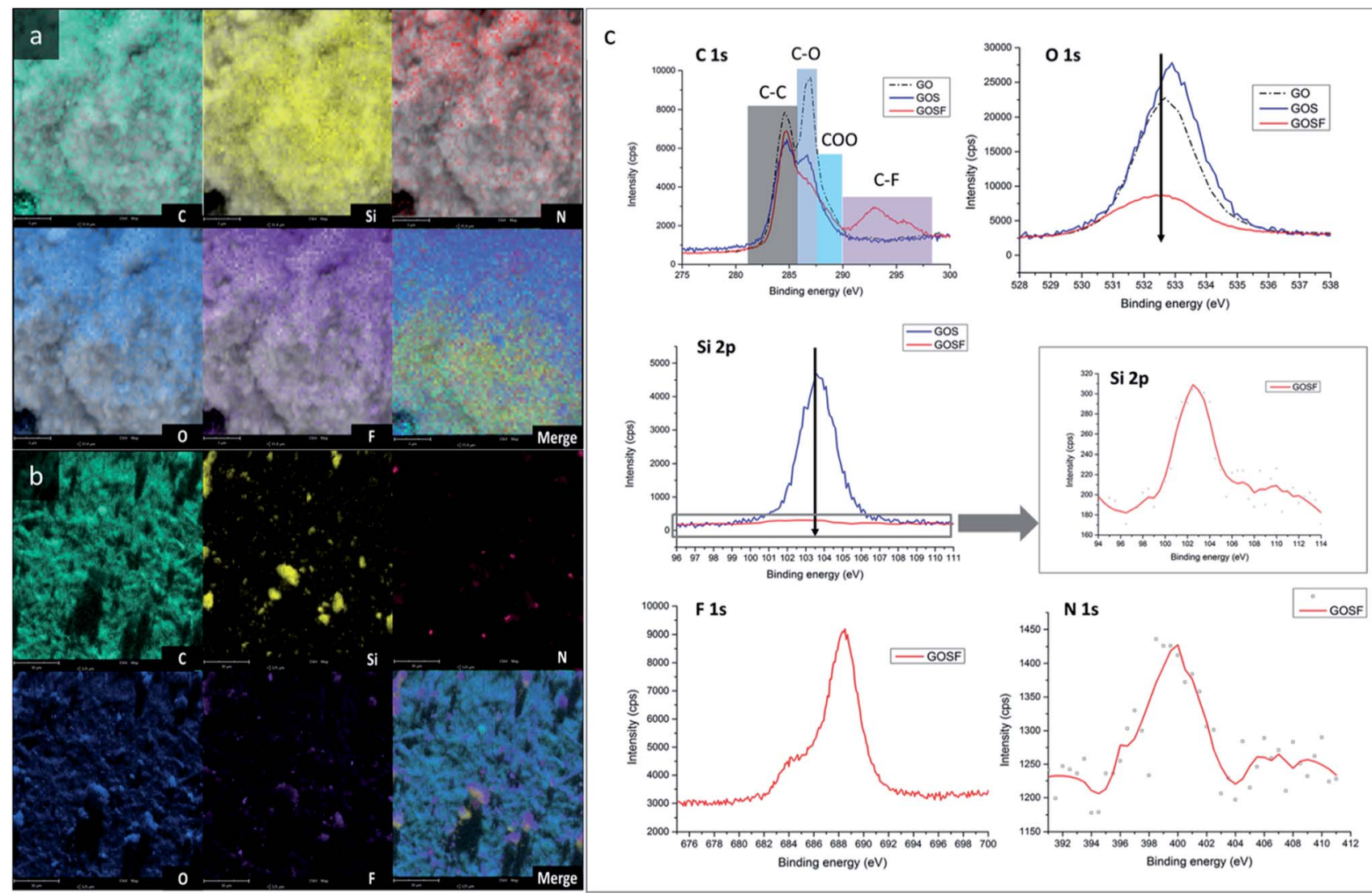

Fig. 7 Surface analysis of GOSF. (a and b) EDX mapping performed in two different zones of GOSF characterized by higher (a), and lower content of silica (b); the scale bar for the mapped zone of panel (a) and (b) are respectively $3 \mu \mathrm{m}$ and $30 \mu \mathrm{m}$. (c) XPS results of GOSF with C 1s and O 1s spectra of GO and GOS, and Si 2p spectrum of GOS for comparison. 
Finally, XPS analysis was performed in order to evaluate the degree of surface covering after functionalization.

The high resolution XPS spectra collected for GOSF are reported in Fig. 8, together with those of GO and GOS for sake of comparison.

Owing to the surface immobilization of 1 , both $\mathrm{O} 1$ s and $\mathrm{Si}$ $2 p$ signals were found to decrease in GOSF with respect to GOS. The C 1s spectrum of GOSF is significantly different from those of GO and GOS, since it is affected by the remarkable presence of 1. In fact, after fluorination, $\mathrm{C}-\mathrm{O}$ and $\mathrm{C}-\mathrm{O}-\mathrm{O}$ contributions were found to decrease, whereas the peaks associated to $\mathrm{C}-\mathrm{F}$ binding (and obviously not present in GO and GOS) are visible within the range $290-300 \mathrm{eV}$.

Moreover, it is possible to detect in GOSF the signals of $\mathrm{F} 1 \mathrm{~s}$ and $\mathrm{N} 1 \mathrm{~s}$, thus further confirming the presence of fluorinated moieties. More in detail, F 1s XPS spectrum of GOSF shows an asymmetric, strong band located at $688 \mathrm{eV}$, due to organic fluorine, i.e. linked to alkyl and phenyl carbon atoms. The less intense $\mathrm{N}$ 1s signal is centred at $399-400 \mathrm{eV}$ and due to oxadiazole ring, the elemental analysis carried out by XPS is provided in Table 1. According to the results, each molecule of 1 should have a $\mathrm{F} / \mathrm{N}$ ratio $=9.5$. After $\mathrm{SNA}, \mathrm{F} / \mathrm{N}$ ratio in GOSF is
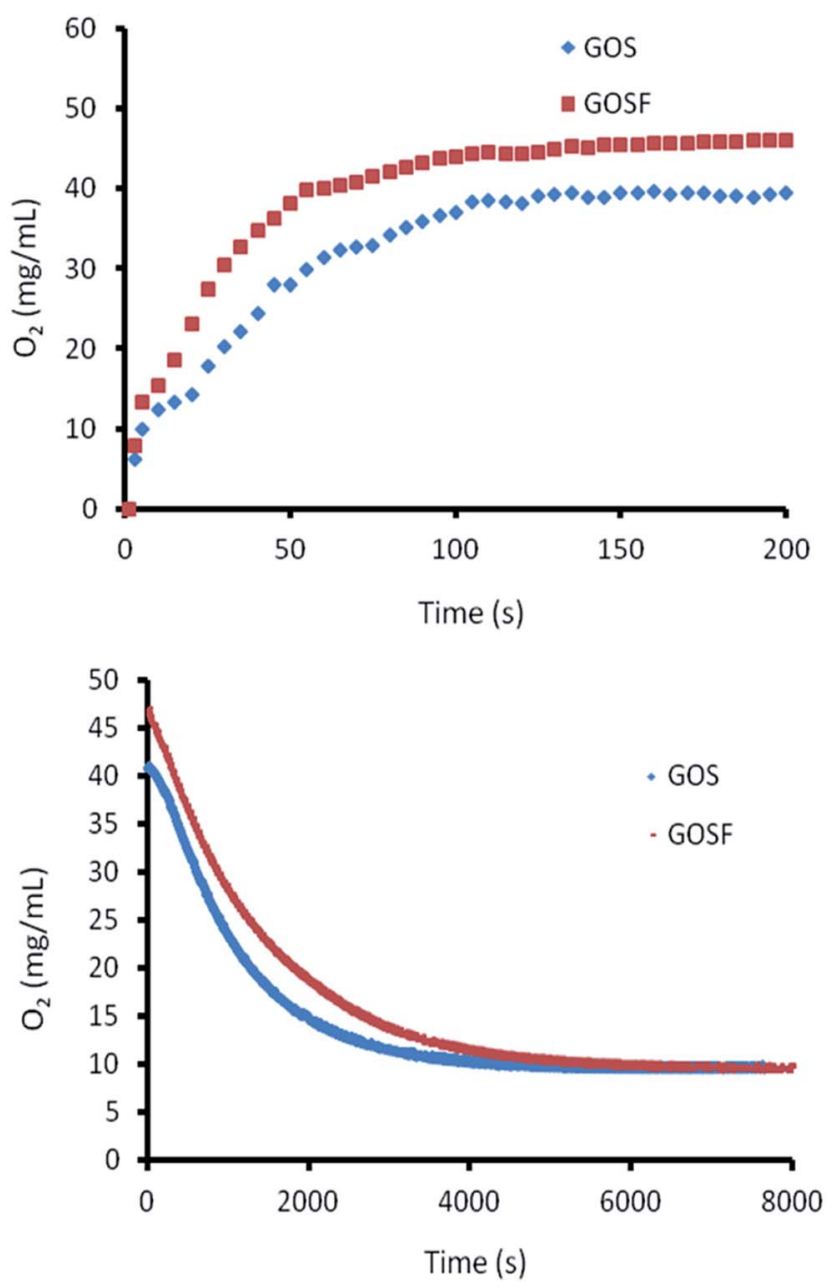

Fig. 8 Oxygen uptake (top) and release (bottom) curves from aqueous solutions containing composites at $25^{\circ} \mathrm{C}$.
Table 1 XPS elemental analysis

\begin{tabular}{llllll}
\hline Sample & $\mathrm{C}(\%)$ & $\mathrm{O}(\%)$ & $\mathrm{N}(\%)$ & $\mathrm{Si}(\%)$ & $\mathrm{F}(\%)$ \\
\hline GO & 60 & 40 & - & - & - \\
Silica & 3 & 59 & - & 38 & - \\
GOS & 54.3 & 37.8 & - & 7.9 & - \\
GOSF & 60 & 22.3 & 1.6 & 1.2 & 14.9 \\
$\mathbf{1}$ & 40.5 & 2.7 & 5.4 & - & 51.4 \\
\hline
\end{tabular}

a bit lower than in $1(\mathrm{~F} / \mathrm{N}$ ratio $=9.31)$, thus confirming the mechanism proposed. Moreover, the analysis allowed to evaluate the degree of surface functionalization $(X)$.

According to eqn (1) and (2) one can express it by taking into account either $\mathrm{F}$ or $\mathrm{N}$ atomic concentration.

$$
\begin{aligned}
& X_{\mathrm{F}}=\mathrm{F} \text { at }{ }^{0}{ }_{\mathrm{GOSF}} / \mathrm{F} \text { at }{ }^{\circ}{ }_{1} \\
& X_{\mathrm{N}}=\mathrm{N} \text { at }{ }^{\circ}{ }_{\mathrm{GOSF}} / \mathrm{N} \text { at } \%_{1}
\end{aligned}
$$

where the subscripts $\mathrm{F}$ and $\mathrm{N}$ stand for the element - fluorine and nitrogen, respectively - atomic percentage used to measure the extent of functionalization.

$X_{\mathrm{F}}(29 \%)$ and $X_{\mathrm{N}}(29.6 \%)$ were found substantially coincident. Based on these findings, the fluorinated moiety attached onto the surface was around $30 \%$ and the decrease of Si and O signals seems to suggests that $\mathbf{1}$ is covalently bonded to both graphene and silica.

In order to obtain some information about the influence of prepared materials on $\mathrm{O}_{2}$ solubility, oxygen uptake and release kinetics were performed on oxygen saturated aqueous solutions containing GOS or GOSF $\left(0.5 \mathrm{mg} \mathrm{mL}^{-1}\right)$ in suspension at atmospheric pressure by means of a previously reported saturation method,,$^{33-36}$ at $25{ }^{\circ} \mathrm{C}$ and at $0.5 \mathrm{mg} \mathrm{mL}^{-1}$. Oxygen solubility was determined after saturation of the medium and monitored as a function of time, at atmospheric pressure. Accordingly to previously reported in vivo experiments, ${ }^{42}$ saturation curves were fitted by eqn (3), while desaturation curves were approximated, by eqn (4).

$$
\begin{gathered}
{\left[\mathrm{O}_{2}\right]=\left[\mathrm{O}_{2}\right]_{\infty}[1-\exp (t / k)]} \\
{\left[\mathrm{O}_{2}\right]=\left[\mathrm{O}_{2}\right]_{\infty}+\left[\mathrm{O}_{2}\right]_{\text {load }} \exp (-t / k)}
\end{gathered}
$$

where: $\left[\mathrm{O}_{2}\right]_{\infty}=$ oxygen solubility at $t_{\infty} ;\left[\mathrm{O}_{2}\right]_{\text {load }}=\left[\mathrm{O}_{2}\right]_{0}-\left[\mathrm{O}_{2}\right]_{\infty}$ where $\left[\mathrm{O}_{2}\right]_{0}=$ oxygen solubility at $t_{0} ; k=$ clearance constant $(\mathrm{s})$.

The data obtained are reported in Table 2 and in Fig. 8.

Table 2 Parameters of eqn (1) and (2) determined for desaturation or saturation curves as a function of time (calculated $P<6 \times 10^{-4}$ )

\begin{tabular}{llll}
\hline Substrate & & GOS & GOSF \\
\hline Saturation parameters & {$\left[\mathrm{O}_{2}\right]_{\infty}{ }^{a}$} & $40.0 \pm 0.3$ & $45.72 \pm 0.02$ \\
& $k^{b}$ & $-39.6 \pm 1.2$ & $-27.8 \pm 0.8$ \\
Desaturation & {$\left[\mathrm{O}_{2}\right]_{0}{ }^{a}$} & $43.34 \pm 0.01$ & $47.67 \pm 0.01$ \\
parameters & {$\left[\mathrm{O}_{2}\right]_{\infty}{ }^{a}$} & $9.49 \pm 0.01$ & $9.41 \pm 0.01$ \\
& $k^{b}$ & $1070.4 \pm 1.0$ & $1396.6 \pm 0.6$
\end{tabular}

${ }^{a}$ Expressed in ppm. ${ }^{b}$ Expressed in seconds. 
Data from Table 2 highlight that fluoro-functionalization increases the dissolved oxygen content at saturation. Notably, for GOSF we observe a faster $\mathrm{O}_{2}$ uptake than unfluorinated GOS and a slower $\mathrm{O}_{2}$ release during desaturation.

Moreover, from these data we can observe a higher saturation value and clearance constant $k$ for GOSF, if compared to fluorinated polymers ${ }^{35}$ and perfluorinated surfactants, such as structures analogue to $\mathbf{1}$ and potassium perfluorooctanoate, ${ }^{36}$ recently reported in the literature for biomedical applications.

\section{Conclusions}

In summary, the synthesis of a novel nanohybrid material has been easily realized by combination of graphene oxide, silica and perfluorinated heterocyclic moieties.

We adopted an eco-friendly pathway to decorate GO lamellae with silica nanoparticles, aiming at improving the stability and biocompatibility of GO and maximizing the - $\mathrm{OH}$ content, thus allowing the selective conjugation of GOS with fluorotails via a SNA mechanism.

Data collected confirm the hypothesis of covalent bonding between the hybrid matrix and the fluorinated moieties.

With respect to the other fluorination routes, exploiting carboxyl and/or epoxy groups, the method here proposed allows achieving a significant functionalization degree, since $-\mathrm{OH}$ end groups are more abundant than $-\mathrm{COOH}$ in the $\mathrm{GO}$ and, of course, in a GO-silica matrix. Furthermore, this pathway allows preserving the structure of the perfluorinated moieties, thus permitting to selectively introduce specific molecules in order to design the desired final properties. In this case we have chosen the oxygen affinity, but we could follow an analogue route to attach different tails for different applications. Finally, the fluorinated GO-silica herein synthesized shows a remarkably high oxygen affinity, double-folded with respect to other fluorinated systems recently reported in literature for the same purposes, ${ }^{33-36}$ due to the synergistic effect of silica nanoparticles and perfluorinated oxadiazole tails. Observed differences, in terms of $k$ values, suggest the constitution of a fluorinated phase, thus enhancing the oxygen exchange.

Moreover, the presence of graphene oxide leads to the achievement of free-standing, lightweight thin films, thus allowing to prepare devices that can be easily re-collected and recycled after being used.

The success of the present preliminary study promises to use these novel nanohybrid thin films as oxygen reservoirs for a wide range of applications, concerning biomedical devices, such as oxygen delivery systems, water treatment membranes, fillers for functional nanocomposites.

\section{Acknowledgements}

We acknowledge Prof S. P. Agnello for valuable discussion, Dr B. Megna for the micro-Raman tests and Dr M. Scopelliti for the XPS analysis. Funding Sources: University of Palermo, FFR 2012-2013 ATE 0291 "Synthesis and characterization of organic salts as functional ionic phases". HIPPOCRATES PON02_00355.

\section{Notes and references}

1 W. S. Hummers and R. E. Offeman, Preparation of Graphitic Oxide, J. Am. Chem. Soc., 1958, 80, 1339.

2 D. C. Marcano, D. V. Kosynkin, J. M. Berlin, A. Sinitskii, Z. Sun, A. Slesarev, L. B. Alemany, W. Lu and J. M. Tour, Improved Synthesis of Graphene Oxide, ACS Nano, 2010, 4, 4806-4814.

3 D. Li, M. B. Mueller, S. Gilje, R. B. Kaner and G. G. Wallace, Processable Aqueous Dispersions of Graphene Nanosheets, Nat. Nanotechnol., 2008, 3, 101-105.

4 G. Eda, G. Fanchini and M. Chhowalla, Large-area Ultrathin Films of Reduced Graphene Oxide as a Transparent and Flexible Electronic Material, Nat. Nanotechnol., 2008, 3, 270-274.

5 I. Rodriguez-Pastor, G. Ramos-Fernandez, H. Varela-Rizo, M. Terrones and I. Martin-Gullon, Towards the understanding of the graphene oxide structure: How to control the formation of humic- and fulvic like oxidized debris, Carbon, 2015, 84, 299-309.

6 A. M. Dimiev, L. B. Alemany and J. M. Tour, Graphene oxide. Origin of acidity, its instability in water, and a new dynamic structural model, ACS Nano, 2013, 7, 576-588.

7 J. P. Rourke, P. A. Pandey, J. J. Moore, M. Bates, I. A. Kinloch, R. J. Young and N. R. Wilson, The Real Graphene Oxide Revealed: Stripping the Oxidative Debris from the Graphene-like Sheets, Angew. Chem., Int. Ed., 2011, 50, 3173-3177.

8 A. M. Dimiev and T. A. Polson, Contesting the twocomponent structural model of graphene oxide and reexamining the chemistry of graphene oxide in basic media, Carbon, 2015, 93, 544-554.

9 J. P. Rourke and N. R. Wilson, Letter to the Editor: A defence of the two-component model of graphene oxide, Carbon, 2016, 96, 339-341.

10 P. Chantharasupawong, R. Philip, N. T. Narayanan, P. M. Sudeep, A. Mathkar, P. M. Ajayan and J. Thomas, Optical Power Limiting in Fluorinated Graphene Oxide: An Insight into the Nonlinear Optical Properties, J. Phys. Chem. C, 2012, 116, 25955-25961.

11 W. L. Zhang and H. J. Choi, Silica-Graphene Oxide Hybrid Composite Particles and their Electroresponsive Characteristics, Langmuir, 2012, 28, 7055-7062.

12 S. Yang, L. Zhi, K. Tang, X. Feng, J. Maier and K. Müllen, Efficient Synthesis of Heteroatom (N or S)-Doped Graphene Based on Ultrathin Graphene Oxide-Porous Silica Sheets for Oxygen Reduction Reactions, Adv. Funct. Mater., 2012, 22, 3634-3640.

13 H. Bao, L. Zhang and G. Chen, Immobilization of Trypsin via Graphene Oxide-silica Composite for Efficient Microchip Proteolysis, J. Chromatogr. A, 2013, 1310, 74-81.

14 C. Li, Y. Zhu, S. Wang, X. Zhang, X. Yang and C. Li, Enhanced Fluorescence of Graphene Oxide by Well-Controlled $\mathrm{Au@SiO}$ Core-Shell Nano-particles, J. Fluoresc., 2014, 24, 137-141.

15 A. Maio, S. P. Agnello, R. Khatibi, L. Botta, A. Alessi, A. Piazza, G. Buscarino, A. Mezzi, G. Pantaleo and 
R. Scaffaro, A Rapid and Eco-Friendly Route to Synthesize Graphene-Doped Silica Nanohybrids, J. Alloys Compd., 2016, 664, 428-438.

16 Y. Hang Hu, The First Magnetic-Nanoparticle-Free CarbonBased Contrast Agent of Magnetic-Resonance ImagingFluorinated Graphene Oxide, Small, 2014, 10, 1451-1452.

17 R. Romero-Aburto, T. N. Narayanan, Y. Na-gaoka, T. Hasumura, T. M. Mitcham, T. Fukuda, P. J. Cox, R. R. Bouchard, T. Maekawa, D. S. Ku-mar, S. V. Torti, S. A. Mani and P. M. Ajayan, Fluorinated Graphene Oxide; a New Multimodal Material for Biological Applications, Adv. Mater., 2013, 25, 5632-5637.

18 A. Mathkar, T. N. Narayanan, L. B. Alemany, P. Cox, P. Nguyen, G. Gao and P. Chang, Synthesis of Fluorinated Graphene Oxide and its Amphiphobic Properties, Part. Part. Syst. Charact., 2013, 30, 266-272.

19 K. Samanta, S. Some, Y. Kim, Y. Yoon, M. Min, S. Lee, Y. Park and H. Lee, Highly Hydrophilic and Insulating Fluorinated Reduced Graphene Oxide, Chem. Commun., 2013, 49, 89918993.

20 M. P. Krafft, Fluorocarbon and fluorinated amphiphiles in drug delivery and biomedical research, Adv. Drug Delivery Rev., 2001, 47, 209-228.

21 X. W. Tan, B. Thompson, A. Konstantopoulos, T. W. Goh, M. Setiawan, G. Hin-Fai Yam, D. Tan, K. A. Khor and J. S. Mehta, Invest. Ophthalmol. Visual Sci., 2015, 56, 66056611.

22 A. Valles Lluch, G. Gallego Ferrer and M. Monleon Pradas, Biomimetic apatite coating on $\mathrm{P}(\mathrm{EMA}-\mathrm{co}-\mathrm{HEA}) / \mathrm{SiO}_{2}$ hybrid nanocomposites, Polymer, 2009, 50, 2874-2884.

23 A. A. Tandara and T. A. Mustoe, Oxygen in wound healing more than a nutrient, World J. Surg., 2004, 28, 294-300.

24 A. Palumbo Piccionello, A. Pace, P. Pierro, I. Pibiri, S. Buscemi and N. Vivona, On the Reaction of Some 5Polyfluoroaryl-1,2,4-Oxadiazoles with Methylhydrazine: Synthesis of Fluorinated Indazoles, Tetrahedron, 2009, 65, 119-127.

25 A. Pace, I. Pibiri, S. Buscemi and N. Vivona, Molecular Rearrangements of 1-Oxa-2-azoles as an Expedient Route to Fluorinated Heterocyclic Compounds, Heterocycles, 2004, 63, 2627-2648.

26 A. Pace, A. Palumbo Piccionello, I. Pibiri, S. Buscemi and N. Vivona, Chemistry of Fluorinated Oxadiazoles and Thiadiazoles, in Fluorine in Heterocyclic Chemistry, ed. V. Nenajdenko, Springer International Publishing, Switzerland, 2014, vol. 1, pp. 369-417.

27 L. Lentini, R. Melfi, A. Di Leonardo, A. Spinello, G. Barone, A. Pace and I. Pibiri, Toward a Rationale for the PTC124 (Ataluren) Promoted Readthrough of Premature Stop Codons: A Computational Approach and GFP-Reporter Cell-Based Assay, Mol. Pharmaceutics, 2014, 11, 653-664.

28 I. Pibiri, L. Lentini, R. Melfi, G. Gallucci, A. Pace, A. Spinello, G. Barone and A. Di Leonardo, Enhancement of Premature Stop Codon Readthrough in the CFTR Gene by Ataluren (PTC124) Derivatives, Eur. J. Med. Chem., 2015, 101, 236-244.
29 F. Lo Celso, I. Pibiri, A. Triolo, R. Triolo, A. Pace, S. Buscemi and N. Vivona, Study on the Thermotropic Properties of Highly Fluorinated 1,2,4-Oxadiazolylpyridinium Salts and their Perspective Applications as Ionic Liquid Crystals, J. Mater. Chem., 2007, 17, 1201-1208.

30 J. P. Critchley and J. S. Pippett, The Synthesis and Stability of Some Perfluoroalkyl- and Perfluoroalkylene-1,2,4- and 1,3,4Oxadiazoles, J. Fluorine Chem., 1973, 2, 137-156.

31 A. Maio, R. Fucarino, R. Khatibi, L. Botta, S. Rosselli, M. Bruno and R. Scaffaro, Graphene Oxide-silica Nanohybrids as Fillers for PA6 Based Nanocomposites, AIP Conf. Proc., 2014, 1599, 438.

32 A. Maio, R. Fucarino, R. Khatibi, S. Rosselli, M. Bruno and R. Scaffaro, A novel approach to prevent graphene oxide reaggregation during the melt compounding with polymers, Compos. Sci. Technol., 2015, 119, 131-137.

33 S. Buscemi, A. Pace, A. Palumbo Piccionello and N. Vivona, Synthesis of Fluorinated First Generation Starburst Molecules Containing a Triethanolamine Core and 1,2,4Oxadiazoles, J. Fluorine Chem., 2006, 127, 1601-1605.

34 P. C. Rooney and D. D. Daniels, Oxygen Solubility in Various Alkanolamine/Water Mixtures, Petrol Tech. Q., 1998, 3, 97101.

35 F. S. Palumbo, M. Di Stefano, A. Palumbo Piccionello, C. Fiorica, G. Pitarresi, I. Pibiri, S. Buscemi and G. Giammona, Perfluorocarbon Functionalized Hyaluronic Acid Derivatives as Oxygenating Systems for Cell Culture, RSC Adv., 2014, 4, 22894-22901.

36 A. Palumbo Piccionello, A. Guarcello, A. Calabrese, I. Pibiri, A. Pace and S. Buscemi, Synthesis of fluorinated oxadiazoles with Gelation and Oxygen Storage Ability, Org. Biomol. Chem., 2012, 10, 3044-3052.

37 R. Scaffaro, A. Maio and A. C. Tito, High performance PA6/ CNTs nanohybrid fibers prepared in the melt, Compos. Sci. Technol., 2012, 72, 1918-1923.

38 A. Maio, L. Botta, A. C. Tito, L. Pellegrino, M. Daghetta and R. Scaffaro, Statistical Study of the Influence of CNTs Purification and Plasma Functionalization on the Properties of Polycarbonate-CNTs Nanocomposites, Plasma Processes Polym., 2014, 11, 664-677.

39 R. Scaffaro, A. Maio, S. P. Agnello and A. Glisenti, Plasma Functionalization of Multiwalled Carbon Nanotubes and their Use in the Preparation of Nylon 6-Based Nanohybrids, Plasma Processes Polym., 2012, 9, 503-512.

40 R. Scaffaro, A. Maio, F. Lopresti, D. Giallombardo, L. Botta, M. L. Bondì and S. P. Agnello, Synthesis and self-assembly of a PEGylated-graphene aerogel, Compos. Sci. Technol., 2016, 128, 193-200.

41 R. Scaffaro and A. Maio, Enhancing the mechanical performance of polymer based nanocomposites by plasmamodification of nanoparticles, Polym. Test., 2012, 31, 889894.

42 B. A. Berkowitz, C. A. Wilson and D. L. Hatchell, Oxygen Kinetics in the Vitreous Substitute perfluorobutylamine: a ${ }^{19}$ F NMR study in vivo, Invest. Ophthalmol. Visual Sci., 1991, 32, 2382-2387. 